\title{
Leukaemoid reaction in a case of leiomyosarcoma of the bladder
}

\author{
Ambati S. Narayana* \\ M.D., M.S., F.R.C.S.(Ire)
}

\author{
D. G. KELLY \\ M.Ch., F.R.C.S.(Ire)
}

\author{
F. A. DufF \\ M.Ch., F.R.C.S.(Ire) \\ Department of Urology, St Vincent's Hospital, Dublin 4, Ireland
}

\begin{abstract}
Summary
The first case of leiomyosarcoma of the urinary bladder associated with leukaemoid reaction is herein presented. There was no secondary involvement of bone marrow to explain the leukaemoid reaction. It may have been due either to tumour necrosis or to an unknown humoral substance elaborated by the tumour.
\end{abstract}

\section{Introduction}

In leukaemoid reaction, changes occur in the peripheral blood similar to those in leukaemia, but are due to other causes, usually infectious, neoplastic or toxic (Fahey, 1951). Characteristically there is a leukocytosis with immaturity of a particular cell type, but the total white cell count may be normal or low. Most leukaemoid reactions are neutrophilic, but they may also be eosinophilic, monocytic, basophilic, or lymphocytic. The total white cell count is usually between $50 \times 10^{9} / 1$ and $100 \times 10^{9} / 1$ and is rarely greater (Finch, 1972).

Neutrophil leukaemoid reactions due to tumours have been recognized for a long time, most commonly reported in association with lung, breast and stomach neoplasms (Fahey, 1951; Barry and Salmon, 1969). There is no reported case of leiomyosarcoma of the urinary bladder associated with leukaemoid reaction. Such a case is now reported.

\section{Case report}

A 69-year-old female was referred to the authors on March 21, 1973, with a 6-month history of painless haematuria. She had also lost $6.7 \mathrm{~kg}$ in weight in the same period, but had no other urinary symptoms. She had previously had excellent health. Physical examination showed nothing abnormal. Haemoglobin was $10.4 \mathrm{~g} / \mathrm{dl}$; ESR $76 \mathrm{~mm}$ in the first hour;

\footnotetext{
* Present address: Department of Urology, University of Iowa Hospitals and Clinics, Iowa City, Iowa.

Address for reprints: Ambati S. Narayana, M.D., M.S., F.R.C.S., Department of Urology, University of Iowa Hospitals and Clinics, Iowa City, Iowa 52242.
}

PCV $33 \%$; WBC $42 \times 10^{\circ} / 1$ (neutrophils $91 \%$ ). Myelocytes and metamyelocytes were seen in the peripheral blood smear. The leukocyte alkaline phosphatase level was markedly elevated. Examination of a bone marrow aspirate confirmed the possibility of a leukaemoid reaction. Her urine grew Escherichia coli, and she was treated successfully with a course of co-trimoxazole. An intravenous pyelogram performed at this time showed a normal upper urinary tract, but a large filling defect was seen in the bladder.

At cystoscopy, a large, mobile, bulky tumour waso found to be arising from the left side of the bladder. A partial cystectomy was performed, and histology? of the tumour revealed that it was a leiomyosarcoma (Fig. 1). The other pelvic viscera were normal.

Her post-operative course was uneventful, and a repeat WBC had decreased to $16.5 \times 10^{\circ} / 1$ with $81 \%$ neutrophils. She was discharged home on April 9 1973.

She was readmitted on May 4 1973, the haematuria having returned one week previously, associated with extreme frequency. A large, hard mass was palpable suprapubically, fixed in the pelvis and also to the anterior abdominal wall. Cystoscopy revealed a large recurrence of the tumour involving most of the left lateral wall of the bladder.

Her WBC on admission was $60 \times 10^{9} / 1$, which rose the following day to $90.2 \times 10^{9} / 1$, with $95 \%$ neutrophils. Myelocytes and metamyelocytes were again seen in the peripheral blood, with some toxic granulation. A repeat WBC 3 days after admission was $80 \cdot 5 \times 10^{9} / 1$. The bladder tumour, which appeared to be undergoing massive necrosis, was deemed inoperable, and the patient was treated with the following chemotherapeutic agents: 5-fluorouracil, $500 \mathrm{mg}$ intravenously for 4 days; vincristine, $1 \mathrm{mg}$ intravenously on the first day; prednisone, $10 \mathrm{mg}$ q.i.d. orally; and chlorambucil, $10 \mathrm{mg}$ orally for 10 days. During treatment repeat WBC levels were recorded at $16.7 \times 10^{9} / 1,9.7 \times 10^{9} / 1$ and $5.3 \times 10^{9} / 1$. 


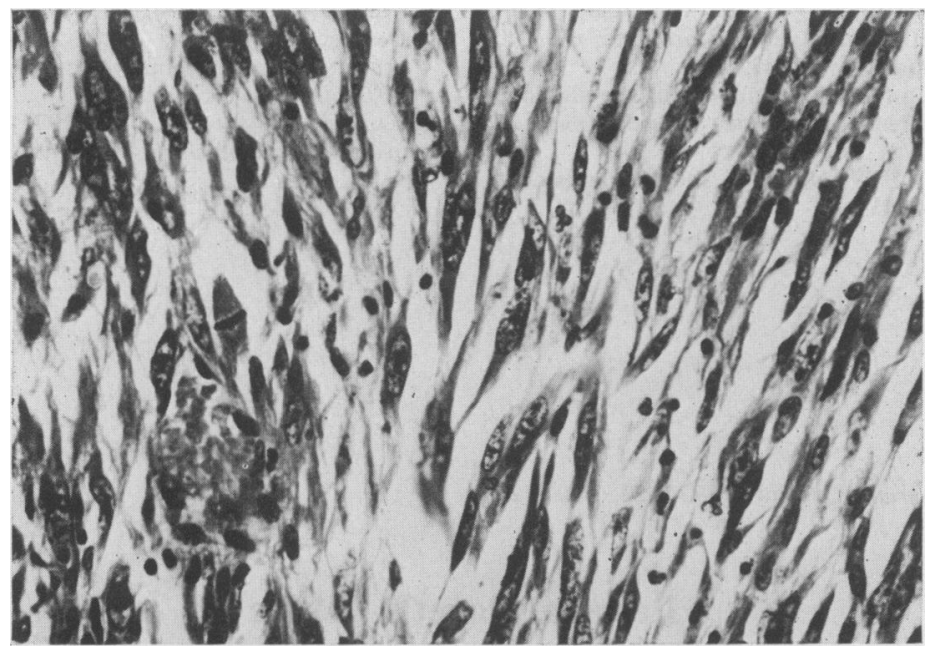

FIG. 1. Leiomyosarcoma of the urinary bladder showing spindle-shaped tumour cells with marked nuclear abnormality and prominent nucleoli $(\times 455)$.

Her condition deteriorated in spite of chemotherapy, and she died following an acute myocardial infarction on May 21 1973. Post-mortem examination revealed that the bladder was almost completely replaced by neoplastic tissue, which extended up through the incision scar and along the anterior abdominal wall. The uterus was almost totally involved with a necrotic tumour mass. The bone marrow was free of metastases.

\section{Discussion}

Krumbhaar (1926) used the term leukaemoid reaction to describe a haematological entity which closely resembled leukaemia. Since then it has been described as occurring in a number of different conditions. The authors have not come across any reports of it in association with leiomyosarcoma of the bladder, although it has been noted with carcinoma of the bladder (Block and Whitmore, 1973).

The first theory as to its causation in relation to tumours was put forward in 1936 by Reich, where a leukaemoid reaction was found in association with a case of adenocarcinoma of the sigmoid colon and bone marrow metastases. In the present case, no such metastases were found, despite a thorough search. Polak and Nemec (1959) postulated that a humoral substance was elaborated from tumours, and this caused the leukaemoid reaction.

Fahey (1951) suggested that actual necrosis of the tumour caused the leukaemoid reaction. In the present case, massive necrosis was noted, and the post-mortem revealed that the entire bladder and uterus was replaced by necrotic tumour, indicating progression of the tumour in spite of chemotherapy.

Sarcomas of the bladder are rare and have been found in 0.38 and $0.67 \%$ of bladder tumours (Tara and Mentur, 1973). In a collection of 324 cases of cystic sarcoma, leiomyosarcoma was the commonest type $(13.5 \%$ ) (Powers, Van Zandt Hawn and Carter, 1956). They tend to invade locally and metastasize rapidly via the blood stream. The progression of the tumour is fast, and the prognosis is poor, although cures have been reported (Tara and Mentur, 1973; Brown, 1965; MacKenzie, Whitmore and Melamed, 1968).

\section{References}

BARRY, R.E. \& SAlmon, P.R. (1969) Recurrent leukemoid reaction in pernicious anaemia complicated by carcinoma of the stomach. British Medical Journal, 2, 612.

BLOCK, N.L. \& WhitMORE, W.F. (1973) Leukemoid reaction, thrombocytosis and hypercalcemia associated with bladder cancer. Journal of Urology, 110, 660.

BRown, H.E. (1965) Leiomyosarcoma of the urinary bladder-follow-up report of two cases with 4 and 10 years' survival. Journal of Urology, 94, 247.

FAHEY, R.J. (1951) Unusual leukocyte response in primary carcinoma of the lung. Cancer. New York, Philadelphia, etc., 4, 930 .

FINCH, S.C. (1972) Granulocytosis. In: Hematology (Ed. by W. J. Williams, O. E. Beutler, A. J. Erslev and R. W. Rundles), 7th edn, p. 654. McGraw-Hill Book Company, New York.

KRUMBHAAR, E.B. (1926) Leukemoid blood picture in various clinical conditions. American Journal of Medical Science, $172,519$. 
MacKenzie, A.F., Whitmore, W.I. \& Melamed, M.R. (1968) Myosarcoma of the bladder and prostate. Cancer. New York, Philadelphia, etc., 22, 833.

REICH, C. (1936) A case of adenocarcinoma of the sigmoid colon with lymphatic leukemia blood picture. American Journal of Cancer, 26, 781.

PolaK, H. \& Nemec, J. (1959) Notes on the mechanism of leukocytosis. Blood, 14, 931.
Powers, J.H., Van Zandt Hawn, C. \& Carter, R.D. (1956) Osteogenic sarcoma and traditional cell carcinoma occurring simultaneously in the urinary bladder. Journal of Urology, 76, 263.

TARA, H.H. \& Mentur, N.L. (1973) Leiomyosarcoma of the urinary bladder. Urology, 11, 460.

\section{Perianal Paget's disease}

\author{
M. R. LOCK* \\ M.B., F.R.C.S. \\ Sir Alan Parks \\ M.Ch., F.R.C.S., F.R.C.P.
}

D. R. KATZ

M.B., Ch.B.
JAMES P. S. THOMSON

M.S., F.R.C.S.

St Mark's Hospital, London

\section{Summary}

Paget's disease involves the ducts of apocrine glands and the overlying epidermis and is considered to be locally neoplastic. It is capable of developing into invasive carcinoma and in this event the prognosis is poor.

The perianal skin may be affected by Paget's disease. This is a rare disorder and the four patients who have been seen with this disease at St Mark's Hospital since 1930 are described.

\section{Introduction}

In 1874 Sir James Paget described fifteen patients in whom the nipple and the surrounding skin of the breast was diseased and who, within 2 years, had developed a clinically recognizable ipsilateral breast carcinoma. The breast is an exocrine gland of the apocrine type and since that time an identical disease process has been found to affect apocrine glands at other sites. These include those situated in the skin of the axilla, the lower eyelid (Glands of Moll), the external genitalia and the perianal region (Glands of Gay).

During the last 50 years only four patients at St Mark's Hospital have been diagnosed as having Paget's disease of the perianal skin. The purpose of

\footnotetext{
*Reprint requests: Surgical Unit, Westminster Hospital, London.
}

this paper is to describe their clinical history and pathology, and to draw attention to this rare condition which should be considered in the differential diagnosis of perianal disorders.

\section{Case reports}

Case 1

Mr W.R. presented in 1959 , aged 64 , with a 5month history of perianal soreness and irritation together with mucoid discharge. Examination showed a raw hyperaemic area $2 \mathrm{~cm}$ in diameter to the right of the anus. Rectal examination and sigmoidoscopy were otherwise normal and no inguinal lymph nodes were palpable. Biopsy showed the appearance of Paget's disease and local excision of the diseased skin was performed. In 1961 an adenoma was removed from the lower rectum and in 1963 his symptom of perianal soreness returned. Biopsy again showed that this was due to Paget's disease. No further treatment was undertaken at this time but he was kept under regular review. In 1967 two areas of induration were noted in the diseased skin which now extended into the lower anal canal for $1 \mathrm{~cm}$ and around the anus for $7.5 \mathrm{~cm}$. Further biopsies were performed, these again showed the changes of Paget's disease but there was no evidence of invasive carcinoma. A wide excision of the diseased perianal skin was performed and the defect covered 